\title{
Zur Abwehr.
}

Von

L. Mohr.

(Der Redaktion zugegangen am 26. September 1906.)

Zu meinem Bedauern bin ich genötigt, auch zu den letzten Äußerungen von $A b d e r h a l d e n$ und Schittenhelm ') über meine Arbeit ${ }^{2}$ ) und über meine Bemerkungen zu ihrem Aufsatz ${ }^{3}$ ) Stellung zu nehmen.

Abderhalden und Schittenhelm sind zuletzt zwar meiner Forderung nachgekommen, den Sachverhalt, der in meiner Arbeit niedergelegt ist, richtig wiederzugeben, ihre sKritik hält sich aber wieder nicht an die Sache selbst, sondern behandelt Dinge, die ich nie behauptet habe, und verliert sich in doktrinären Auseinandersetzungen, die der Sache unmöglich förderlich sein können. Ich muß deshalb die fraglichen Punkte nochmals präzisieren.

Nachdem ich aus dem Harn eines pankreaslosen Hundes nach Verabreichung von $10 \mathrm{~g}$ d-Leucin ein Naphtalinsulfoprodukt dargestellt hatte, das krystallinisch rein und einheitlich war und einen hohen Stickstoffgehalt aufwies, habe ich die Vermutung ausgesprochen, daß diese Substanz ein Leucinpeptid sei, und aus dem Befund geschlossen, daß hiermit höchstwahrscheinlich zum erstenmal der Übergang höher molekularen Aminosäuren in den Harn dargetan sei. Ich habe mich bei dieser Schlußfolgerung so verhalten, wie man sich bei biologischen Fragen, und nur um eine solche handelt es sich im vorliegenden Falle, allgemein verhält. Wer in dem Harn eines Menschen nach reichlicher Zufuhr von Traubenzucker eine reduzierende, gărende Substanz findet, die vorher nicht im Harn nachzuweisen war, schließt mit Recht, daß diese Substanz Traubenzucker sei. Nur übertriebene Exaktheit kann in diesem Fall verlangen, daß das Vorhandensein von Traubenzucker durch die chemische Reindarstellung des Traubenzuckers aus dem Harn dargetan wird. In gleicher Lage befinde ich mich, wenn ich die Vermutung ausspreche, daß die in dem Harn des pankreaslosen Hundes nach Verabfolgung von $10 \mathrm{~g}$ Leucin gefundene Naphtalinsulfoverbindung eine Leucinverbindung sei. Denn es ist bisher nicht bekannt, daß verfütterte Aminosäuren, wenn sie unverbrannt den Organismus durchlaufen, nicht in ihrer ursprünglichen Form ausgeschieden würden. Nach Verfütterung von Alanin, von Glykokoll und Leucin wird immer nur, falls diese Substanzen überhaupt im Harn ausgeschieden werden, Alanin bezw. Gly-

1) Diese Zeitschrift, Bd. XLVIII, S. 574-76.

2) Zeitschrift f. exper. Path. u. Ther., Bd. II, S. 666 u. 667.

s) Diese Zeitschrift, Bd. XLVIII, S. 380. 
kokoll bezw. Leucin im Harn gefunden. Meine Vermutung, daß das von mir gefundene Naphtalinsulfoprodukt eine Leucinverbindung sei, gründete sich somit auf die bisher vorliegenden Erfahrungen. Die Forderung, daß ich zur Stütze dieser Vermutung Leucin hätte chemisch isolieren müssen, wie Abderhalden und Schittenhelm verlangen, ist völlig unverständlich, denn falls ich das getan hätte, hätte ich es nicht nötig gehabt, nur vermutungsweise die Anwesenheit von Leucin anzunehmen, sondern ich hätte behaupten können, daß Leucin vorhanden ist. Da ich dies nicht getan habe, sondern im Gegenteil mit aller Vorsicht mich dahin geäußert habe, daß Leucin in peptidartiger Verbindung im Harn vorhanden sei, so ist der Vorwurf Abderhaldens und Schittenhelms, daß meine Annahme ungenügend gestützt sei, hinfällig. Ich betone nochmals, daß es sich im vorliegenden Falle nur um die Führung eines biologischen Wahrscheinlichkeitsbeweises handelt, und daß ich nie behauptet habe, den vollen chemischen Nachweis des Leucins geführt zu haben.

Vom Standpunkte des Biologen aus aber bleibe ich dabei, daß meine Vermutung, es handele sich in meinem Falle mit größter Wahrscheinlichkeit um die Ausscheidung von Leucin, und zwar in einer Form, welche einer peptidartigen Verbindung entspricht, berechtigt ist. Daß es sich bei dem fraglichen Körper um eine höher molekulare Aminosäureverbindung (entsprechend ihrem hohen Stickstoffgehalt) gehandelt hat, könnte nur durch den Nachweis widerlegt werden, daß es im Harn außer Aminosäuren und Ammoniak Substanzen gibt, welche mit Naphtalinsulfochlorid reagieren, charakteristische, einheitliche Krystalle bilden, stickstoffreich sind, in Alkali sich lösen und mit Säuren gefällt werden. Solche Substanzen sind weder mir, noch anscheinend Abderhalden und Schittenhelm bekannt, sonst würden sie ihrer wohl Erwähnung getan haben. Es ist Sache meiner Gegner, diesen Nachweis zu führen, nicht meine Aufgabe. Nur auf der Basis dieses Nachweises kann eine berechtigte objektive Kritik des von mir erhobenen Befundes einsetzen. Die Kritik, welche Abderhalden und Schittenhelm an meiner Arbeit geübt haben, kann auf diese Bezeichnung keinen Anspruch machen. Als Beleg für diese Behauptung führe ich den Schlußsatz ihrer Bemerkungen hier an: -Selbst wenn es in Zukunft gelingen sollte, derartige Synthesen im tierischen Organismus nachzuweisen, so wird Mohrs Befund nicht als erster derartiger Befund gelten dürfen.» Dieser Satz charakterisiert aufs klarste den Geist, der diese ‘Kritik> geschaffen hat, und bestätigt aufs glänzendste, wie recht ich mit der Behauptung hatte, daß das Urteil Abderhaldens und Schittenhelms über meinen Befund von einem einseitigen Standpunkt aus gefällt worden ist.

$\mathrm{Daß}$ ich nach dieser Erfahrung auf weitere Auseinandersetzungen mit $\mathrm{Abderhalden}$ und Schittenhelm verzichte, wird jedermann begreiflich finden. 